\title{
Migration of a Broken Drill Bit After Acetabular Fracture Fixation. A Case Report
}

\author{
Jamot S, MD SpOT, Razif A, FRCS (Edin), Azhar MM, MS Orth (UM), AA Abbas, MS Orth (UM) \\ Department of Orthopedic Surgery, University Malaya Medical Center, Kuala Lumpur, Malaysia
}

\begin{abstract}
Breakage of the drill bit is common in orthopaedic procedures, but migration of the broken drill bit is rarely reported. We report a case of migration of a broken drill bit five years after acetabular fracture fixation. The drill bit migrated to the subcutaneous layer of the anterior aspect of the right hip following total hip replacement. We highlight this case as it could be encountered in any orthopaedic procedure, and we support the recommendation to record such incidences in the medical notes and to inform the patient.
\end{abstract}

\section{INTRODUCTION}

Several authors have reported remote migration of metallic hardware from the proximal humerus and hip joint. Most of these cases involve migrations in the upper extremities, especially from the shoulder girdle and mostly resulting from breakage and migration of $\mathrm{K}$-wires and wires used for fracture fixation ${ }^{1}$. Migration of a broken drill bit is rarely reported, but one study reported that the most common instrument broken in orthopaedic surgeries was a drill bit. The possible causes noted in this study include bending of the drill bit in order to drill cortical bone at an incident angle, wear and tear of the drill bit as a result of repeated use, or due to poor manufacturing technique of the drill bit, all of which could result in increased risk of breakage ${ }^{2}$.

We report a patient with migration of a broken drill bit found five years after fixation for a right acetabular fracture. The aim of this report is to improve our understanding and management of patients who have undergone procedures in which orthopaedic hardware breakage occurs, a common complication in our line of work.

\section{CASE REPORT}

A 28-year- old male was admitted because of a history of pain in the right groin for one year following total hip replacement, and swelling for the few weeks prior to presentation. The pain had worsened over the preceding few days, and was especially tender when sitting and standing.
Five years before this visit, he had sustained a right acetabular fracture and femoral shaft fracture and underwent open reduction and internal fixation with plates and screws for the acetabular fracture and intramedullary interlockingnail for the femoral shaft fracture. The patient was not informed that a drill bit had broken while performing fixation of the acetabulum and that the drill bit had been left in situ.

He began to complain of right hip pain of increasing intensity 3 months later, and was diagnosed to have osteonecrosis of the right femoral head. Radiographs of the right hip also revealed a broken drill bit near the acetabular plate but within the bone. (Figure 1) Following removal of the interlocking nail and two of the three plates, right total hip replacement was performed soon after the review. (Figure 2) His immediate postoperative recovery was uneventful. However, 6 months following the total hip replacement procedure, he began to complain of right groin pain, especially with movement. Despite physiotherapy and analgesia, his pain persisted and a swelling was developing in the groin region.

On physical examination, the right groin appeared swollen with a sharp tip palpable over the swelling. It was extremely tender to touch. Lateral plain radiograph showed migration of the broken drill bit to the subcutaneous tissue anterior to the right hip joint. (Figure 3)

We suspected that this migrated broken drill bit was causing the groin pain and decided to surgically remove the hardware immediately. In the present case, a broken drill bit migrated to the subcutaneous tissue anterior to the acetabulum and could have caused injury to the adjacent femoral nerve or blood vessels. We informed the patient about potential complications if the hardware was not removed and also risks during the surgery to remove it.

We removed the hardware quite easily under local anaesthetic because it was quite superficial. Postoperative recovery was uneventful, and the pain and swelling then resolved completely. 


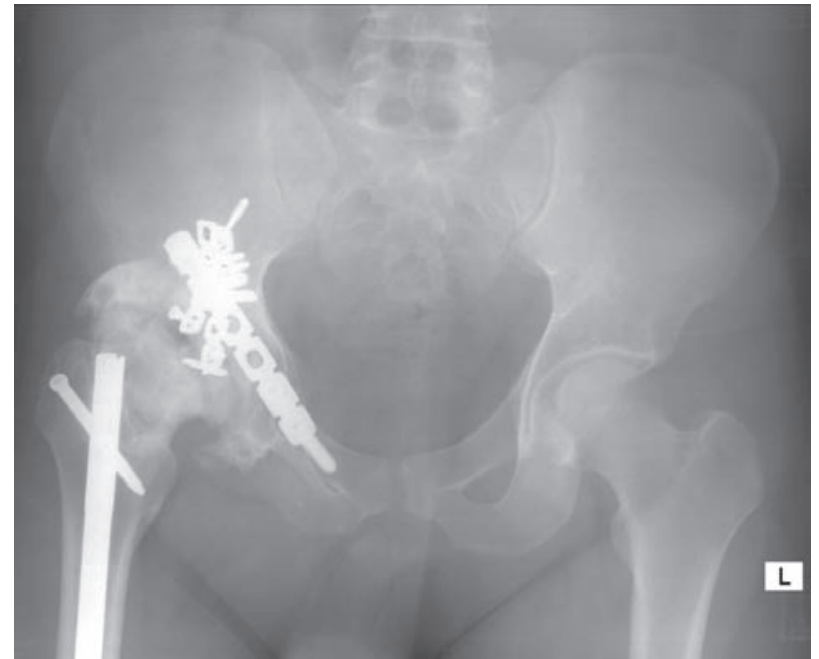

Fig. 1: Plain radiograph shows fixation of right acetabular with multilpe plates and screws and a broken drill bit, IM interlocking-nail for shaft femoral fracture and avascular necrosis of right femoral head (May 2009).

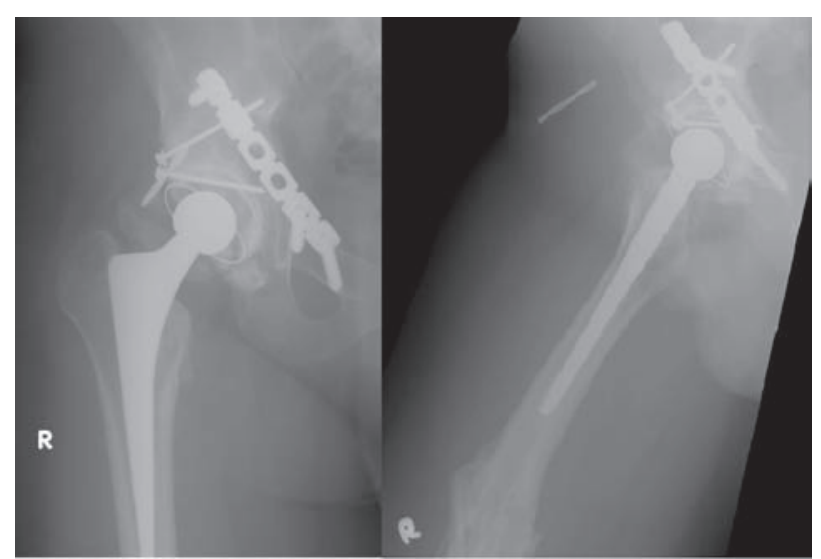

Fig. 3: Plain radiographs show migration of a broken drill bit to the posterolateral aspect of the right hip (September 2010).

\section{DISCUSSION}

There are various reports in the literature of complications due to intra- or postoperative intrapelvic migration of devices used in the internal fixation of hip fractures. These reports include migration of the following: a broken pin into the urinary bladder, a threaded Steinmann pin and a protruding screw from a sliding screw-plate device ${ }^{3}$.

Threaded pins have an increased holding power in bone, and yet there have been reports of their migration from clavicle to the cervical spine ${ }^{4}$. Therefore a broken drill bit which had no threads could migrate quite easily. Drill bits are the most commonly broken orthopaedic hardware according to a study by Price et $a l^{2}$. In addition to drilling cortical bone at an incident angle, wear of the re-used drill bits are likely causes of increased risk of failure ${ }^{2}$. In the case of this patient, similar to reports by Price et al, the drill bit broke

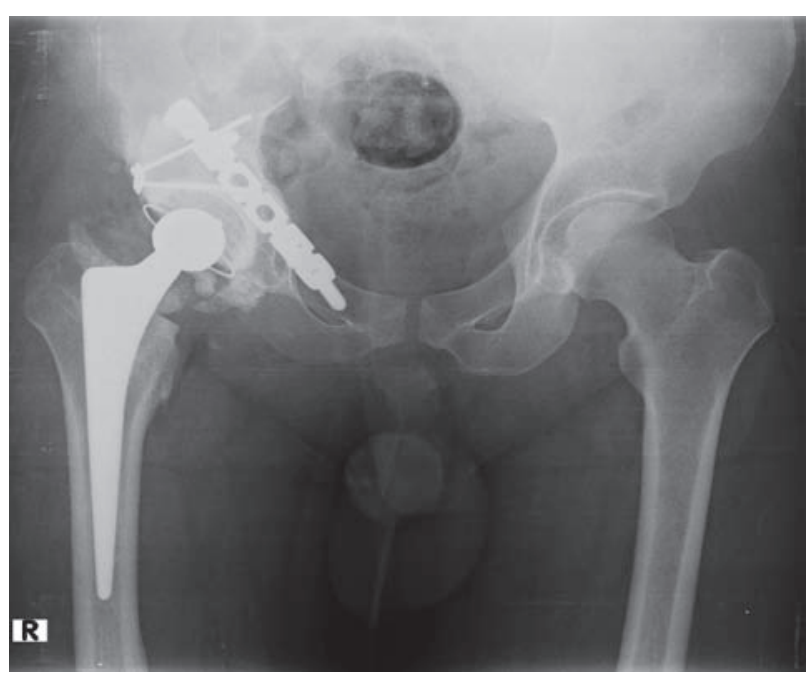

Fig. 2: Plain radiograph after right THR and removal some plates and screw of acetabular fixation (October 2009).

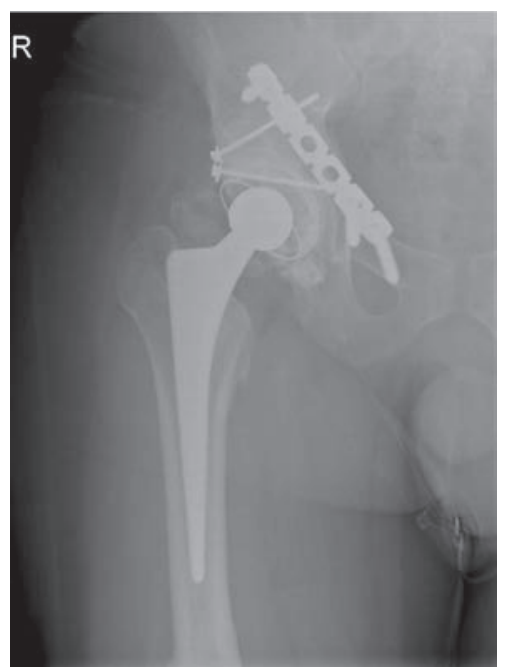

Fig. 4: Plain radiographs after removal of a broken drill bit.

during fixation of the right acetabular fracture, where access to the fracture is limited and the surgeon may have been required to drill the cortical bone at an angle, thus causing the drill bit to bend and break. The drill bits in our institution are also frequently re-used and therefore likely worn.

A literature search about broken orthopaedic implants (Kwires, drill bits etc) revealed a few case reports, which offered some guidelines to management of these cases. A broken drill bit that is not in contact with an implant could be left in the body without any risk of delayed recovery. However, if the drill fragment is situated near a joint or if it could be easily removed without further trauma to the bone, then it should be removed. Once the fracture is healed, the broken drill bit should be removed along with the implant provided no exceptional difficulties are involved ${ }^{5}$. 
In most cases, documentation of this perioperative complication is deficient, and frequently, the patient is not informed $^{2}$. In the present case, the patient was quite upset as he was not told of the broken hardware which remained in his acetabulum and there was no explanation about the complication or risk prior to this presentation. We also found no record in the patient's case notes about the instrument breakage. In this regard, recommendations by Price et al include: adequate documentation in incident logbooks and patient case notes especially concerning location of the broken hardware that remains in the patient; informing the patient of the incident as well as the possible complications (with documentation of same in the case notes); and, reporting the incident to the representative instrument company $^{2}$.

We would also like to add that this complication can be prevented by ensuring adequate working space and exposure when performing fracture repairs. We also recommend that drill bits in particular should be monitored for wear, and replaced frequently. Additionally, the patient should be monitored for any adverse events as a result of the broken hardware. 


\section{REFERENCES}

1. Medved I, Simic O, Bralic M, Stemberga V, Kovacevic M, Matana A et al. Chronic heart perforation with $13.5 \mathrm{~cm}$ long Kirschner wire without pericardial tamponade: an unusual sequela after shoulder fracture. Ann Thorac Surg 2006; 81: 1895-7.

2. Price MV, Molloy S, Sollan MC, Sutton A, Ricketts DM. The rate of instrument brekage during orthopaedic procedures. Int Orthop 2002; 26: 185-7.

3. Brodell JD, Leve AR. Disengagement and intrapelvic protrusion of the screw from a sliding screw-plate device: a case report. $J$ Bone Joint Surg Am 1983; 65: 697-701.

4. Tsai CH, Hsu HC, Huan CY. Late Migration of Threaded Wire (Schanz Screw) from Right Distal Clavicle to the Cervical Spine: a case report. J Chin Med Assoc 2009; 72: 1.

5. Hirt U, Auer JA, Perren SM. Drill bit failure without implant involvement--an intraoperative complication in orthopaedic surgery. Injury 1992; 23(2): 5-16. 